\title{
J ob satisfaction, burnout, and stress among pediatric nurses in various specialty units at an acute care hospital
}

\author{
Michi A. Sekol ${ }^{1}$, Son Chae Kim² \\ 1. Rady Children's Hospital, San Diego, United States. 2. St. David's School of Nursing, Texas State University, Round \\ Rock, Texas, United States.
}

Correspondence: Son Chae Kim. Address: St. David's School of Nursing, Texas State University, 1555 University Blvd, Round Rock, Texas 78665, United States. Email: sck30@txstate.edu

Received: August 8, 2014

Accepted: September 23, 2014

Online Published: October 14, 2014

DOI : $10.5430 /$ jnep.v4n12p115

URL: http://dx.doi.org/10.5430/jnep.v4n12p115

\section{Abstract}

Aims: The aims of the study were to: assess job satisfaction, burnout, compassion satisfaction, and work-related stress among pediatric nurses at surgical, medical, critical care, and hematology/oncology units in a tertiary acute care hospital; and identify the predictors of job satisfaction, burnout, compassion satisfaction, and work-related stress.

Methods: A cross-sectional study was conducted at a children's hospital in southern California from February 2013 to March 2013. A convenience sample of registered nurses working in four different units $(\mathrm{N}=240)$ completed the Professional Quality of Life, Brief Index of Affective Job Satisfaction, and demographic questionnaire. One-way Analysis of Variance (ANOVA) and simultaneous multiple regression procedures were performed.

Results: Nurses in the hematology/oncology unit reported the lowest level of burnout and highest levels of job satisfaction and compassion satisfaction. In contrast, nurses in the surgical unit reported the opposite. Among surgical unit nurses, those with 5-9 years of RN experience reported highest burnout as well as lowest job satisfaction and compassion satisfaction. The combination of demographic variables explained a large fraction of the variance in job satisfaction $\left(R^{2}=\right.$ $0.251)$ and positive predictors were white ethnicity $(\beta=0.33)$ and hematology/oncology unit $(\beta=0.16)$, whereas negative predictors were surgical unit $(\beta=-0.32)$ and critical care unit $(\beta=-0.20)$.

Conclusions: Nurses in the hematology/oncology unit reported lowest burnout and highest job satisfaction, which may be due to the educational and mentoring support from a unit-based end-of-life care program. A focused strategy targeting a specific group of nurses in a unit may help to reduce work-related stress and burnout.

\section{Key words}

Job satisfaction, Compassion satisfaction, Burnout, Stress, Pediatric nurses

\section{I ntroduction}

In spite of the numerous initiatives and programs to improve the quality of healthcare and minimize the preventable adverse outcomes, only a limited progress has been made ${ }^{[1]}$. Nursing shortage may have also exacerbated the quality problem and the shortage is likely to get worse with an estimated deficit of 260,000 nurses in the United States alone by 
$2025^{[2]}$. The International Council of Nurses (ICN) ${ }^{[3]}$ has promoted the positive practice environment, linked to job satisfaction and good patient outcomes, as one of the top priorities to stem the global nursing shortage. Threats to the positive healthy work environment include work-related stress, burnout, and job dissatisfaction, which are not uncommon hazards for nurses and can result in high turnover ${ }^{[4-6]}$. These can add significant hidden costs to organizations, as one nurse turnover can cost $\$ 12,000$ to $\$ 67,0000^{[7]}$.

The work-related stress arises from the high patient acuity, insufficient staffing, perceived lack of managerial support, lack of autonomy, and negative relationships with co-workers ${ }^{[6,8,9]}$. As a consequence, a nurse may experience burnout, which includes feeling emotionally exhausted, detached from the job, and underachieved. This can lead to job dissatisfaction and intent to leave the profession ${ }^{[5,6,10]}$. Nurses' job satisfaction has been used as a strong predictor of retention within an organization and has been directly linked to turnover rates. Stordeur and associates ${ }^{[11]}$ found that nurses working in hospitals with a turnover rate less than $3.1 \%$ in one year had lower levels of burnout, higher levels of job satisfaction, and greater commitment to the organization compared to those in organizations with much higher turnover rates. Negative outcomes related to job dissatisfaction include decreased patient satisfaction and decreased quality of care provided ${ }^{[4,12]}$. As a buffer against burnout, compassion satisfaction refers to the feelings of satisfaction and achievement from helping patients in need that can sustain a nurse through difficult and emotionally painful situations ${ }^{[13,14]}$. Nurses reporting high levels of compassion satisfaction can handle suffering and pain many times over and still can be empathetic ${ }^{[7]}$.

Pediatric hospitals are known to be high-stress workplace environments as the emotional impacts of seeing sick or dying children are often intensified. As nurses may experience overwhelming emotional stress, helplessness, pain, and sadness while working with sick or dying children and their families, they also need to develop specialized skills, qualities arising from compassion and professional commitment, and abilities to handle the stressful situations. Nurses can experience a greater level of burnout than even trauma workers in a children's hospital setting ${ }^{[15]}$. A majority of novice pediatric nurses experience stressful events during their first three months of employment and about one-fifth have displayed symptoms of Post Traumatic Stress Disorder (PTSD) after the first three months at bedside ${ }^{[16]}$. The pediatric nurses working in certain specialty areas, such as the critical care unit or hematology/oncology unit are thought to be more susceptible to burnout. The pediatric oncology nurses reported to have significantly lower level of personal accomplishment in burnout scale compared to adult oncology nurses and one- third of nurses in neonatal intensive care unit reported symptoms of burnout ${ }^{[17-19]}$.

Previous reports have shown that effective personal coping strategies and healthy workplaces can reduce burnout and improve job satisfaction. After an implementation of nursing support program, the turnover rate among new pediatric nurses declined ${ }^{[19]}$. The pediatric critical care nurses who perceived themselves as well-prepared and had the ability to care for dying patients reported higher compassion satisfaction and lower burnout ${ }^{[20]}$. Various strategies of improving self-care, counselling, enhancing group cohesion, and working in magnet hospitals have shown to improve nurses' job satisfaction and reduce burnout among pediatric nurses ${ }^{[5,16,21-24]}$. Most of the pediatric nurses reported that they were able to apply the self-care practices and became better in handling life and work stress after attending a series of educational programs ${ }^{[5]}$. Higher organizational support was reported by pediatric nurses in magnet hospitals compared to those in non-magnet hospitals ${ }^{[21]}$. Although a randomized control study among pediatric oncology nurses showed no significant improvement in their perceived stress or burnout after 8 weekly sessions of a mindfulness training program, they reported less stress, improved compassion, and better self-awareness in qualitative analysis ${ }^{[23]}$.

To minimize burnout from working with sick or dying children and their families, pediatric nurses need to develop coping skills that can be facilitated by professional and organizational supports. Although studies have reported on the workrelated stress, burnout, and job satisfaction, most of these reports have focused on nurses in hematology/oncology or critical care units, leaving a gap in knowledge regarding those working in medical or surgical units. Furthermore, little is known about the extent to which demographic variables such as the unit location or years of work experience impact their perception of job satisfaction, burnout, compassion satisfaction, and work-related stress among pediatric nurses. 


\section{Study aims}

The aims of the study were to: assess job satisfaction, burnout, compassion satisfaction, and work-related stress among pediatric nurses at surgical, medical, critical care, and hematology/oncology units in a tertiary acute care hospital; and identify the predictors of job satisfaction, burnout, compassion satisfaction, and work-related stress.

\section{Methods}

\subsection{Design and participants}

A cross-sectional study was conducted at a children's hospital in southern California from February 2013 to March 2013. The hospital is a non-profit, 520-bed pediatric care facility which is also designated as a pediatric trauma center. As a tertiary acute care pediatric hospital, it provides acute inpatient and outpatient care services, including cancer treatments, peripheral blood and bone marrow transplants, heart surgeries, orthopedics, emergency, and trauma care. A convenience sample of registered nurses working in surgical, medical, critical care, and hematology/oncology units was invited to participate in the study. The inclusion criteria were full-time, part-time, or per diem registered nurses employed at these four units.

\subsection{Instruments}

To assess job satisfaction, burnout, compassion satisfaction, and work-related stress, three instruments were used in the current study: Professional Quality of Life scale, version 5 (ProQOL-V) ${ }^{[24]}$, Brief Index of Affective Job Satisfaction (BIAJS) ${ }^{[25]}$, and a demographics questionnaire. The 30 -item ProQOL-V is a valid and reliable instrument that measures the positive and negative quality of life in relation to the professional work as a helper ${ }^{[24]}$. This instrument consists of three subscales, including Compassion Satisfaction, Burnout, and Secondary Traumatic Stress on 5-point Likert-type response ranging from 1 (never) to 5 (very often). The 10-item Compassion Satisfaction subscale refers to a positive aspect of helping others through one's work and higher scores indicate a greater satisfaction with one's professional role. The 10-item Burnout subscale measures the negative feelings regarding lack of personal accomplishments and emotional exhaustion related to workplace environment or heavy workload. The 10-item Secondary Traumatic Stress subscale measures the stress symptoms from seeing others experience trauma or extremely stressful events. Higher scores for either Burnout or Secondary Traumatic Stress subscales indicate higher levels of burnout or work-related stress. The construct validity of this tool has been reported in the previous published studies. The internal consistency reliabilities of Compassion Satisfaction, Burnout, and Secondary Traumatic Stress subscales were Cronbach's alphas of 0.88, 0.75, and 0.81 , respectively. Each subscale's summation score ranges from 10 to 50 , with scores $\geq 42,23-41$, and $\leq 22$ indicating high, moderate, and low score categories, respectively.

The 7-item Brief Index of Affective Job Satisfaction (BIAJS) includes four items measuring subjective satisfaction with current job plus three distractor items on a 5-point Likert-type response, ranging from 1 (strongly disagree) to 5 (strongly agree) ${ }^{[25]}$. After excluding the distractor items, the mean score ranges from 1 to 5 , with the higher score indicating higher job satisfaction. The internal consistency reliability was reported with Cronbach's alphas ranging from 0.81 to 0.83 . The demographic questionnaire collected information on gender, age, ethnicity, education level, years worked as a registered nurse $(\mathrm{RN})$, and the unit location.

\subsection{Data collection procedures}

The study was approved by the Institutional Review Boards at the hospital and the university. A waiver of consent was granted since the research presented no more than minimal risks and the data collection methods preserved anonymity. The potential subjects were recruited during unit team meetings of the four units. The nurses who agreed to participate in the study were reminded that their participation was entirely voluntary and had the right to withdraw from participation at any time without affecting their employment or relationship with the hospital. The nurses returned the completed questionnaires after the unit team meetings. 


\subsection{Data analyses}

The collected data were entered and analyzed using SPSS program, version 20.0 (SPSS Inc, Chicago, USA). Descriptive statistics of frequencies, percentage, means, and standard deviations were performed. One-way Analysis of Variance (ANOVA) was employed to compare the mean scores of job satisfaction, burnout, compassion satisfaction, and secondary traumatic stress across the four units. Bivariate Pearson correlations were first performed to assess the relationships among demographic variables, job satisfaction, burnout, compassion satisfaction, and secondary traumatic stress. The categorical demographic variables were recoded into dummy variables. The statistically significant demographic variables were then entered simultaneously into multiple regression models to identify the predictors of four dependent variables. For the purpose of this study, the significance level was set at $p$ value $<.05$.

\section{Results}

\subsection{Sample characteristics}

A total of 240 out of 406 nurses employed in the four units participated in the study (59\% responses rate): 39 from surgical, 71 from medical, 39 from critical care, and 46 from hematology/oncology unit. The sample characteristics of each unit are presented in Table 1. A majority of the participants were female (94.2\%), white (66.7\%), 30-44 years old (53.8\%), and had less than 10 years of $\mathrm{RN}$ experience (55.0\%) and baccalaureate degree (70.0\%). There were no significant differences in demographic characteristics across the four units.

Table 1. Sample characteristics across four study units $(\mathrm{N}=240)$

\begin{tabular}{|c|c|c|c|c|c|}
\hline & $\begin{array}{l}\text { Surgical unit } \\
(\mathrm{n}=39)\end{array}$ & $\begin{array}{l}\text { Medical unit } \\
(\mathrm{n}=71)\end{array}$ & $\begin{array}{l}\text { Critical care unit } \\
(\mathrm{n}=39)\end{array}$ & $\begin{array}{l}\text { Hematology/oncology unit } \\
(\mathrm{n}=46)\end{array}$ & $\begin{array}{l}\text { Total } \\
(\mathrm{N}=240)\end{array}$ \\
\hline \multicolumn{6}{|l|}{ Gender } \\
\hline Female & $36(92.3)$ & $65(91.5)$ & $79(94.0)$ & $46(100)$ & $226(94.2)$ \\
\hline Male & $2(5.1)$ & $6(8.5)$ & $5(6.0)$ & $0(0)$ & $13(5.4)$ \\
\hline \multicolumn{6}{|l|}{ Age, yr } \\
\hline $21-29$ & $11(28.2)$ & $13(18.3)$ & $15(17.9)$ & $17(37.0)$ & $56(23.3)$ \\
\hline $30-44$ & $18(46.2)$ & $48(67.6)$ & $43(51.2)$ & $20(43.5)$ & $129(53.8)$ \\
\hline $45-59$ & $8(20.5)$ & $8(11.3)$ & $22(26.2)$ & $7(15.2)$ & $45(18.8)$ \\
\hline$\geq 60$ & $1(2.6)$ & $2(2.8)$ & $4(4.8)$ & $2(4.3)$ & $9(3.8)$ \\
\hline \multicolumn{6}{|l|}{ Ethnicity } \\
\hline White & $29(74.4)$ & $44(62.0)$ & $56(66.7)$ & $31(67.4)$ & $160(66.7)$ \\
\hline Hispanic & $4(10.3)$ & $5(7.0)$ & $5(6.0)$ & $1(2.2)$ & $15(6.3)$ \\
\hline African-American & $2(5.1)$ & $0(0)$ & $0(0)$ & $0(0)$ & $2(0.8)$ \\
\hline Asian & $1(2.6)$ & $16(22.5)$ & $14(16.7)$ & $11(23.9)$ & $42(17.5)$ \\
\hline Multi-ethnic & $2(5.1)$ & $5(7.0)$ & $2(2.4)$ & $3(6.5)$ & $12(5.0)$ \\
\hline Other & $0(0)$ & $1(1.4)$ & $5(6.0)$ & $0(0)$ & $6(2.5)$ \\
\hline \multicolumn{6}{|l|}{ Educational level } \\
\hline Diploma/Associate & $8(20.5)$ & $12(16.9)$ & $19(22.6)$ & $6(13.0)$ & $45(18.8)$ \\
\hline Baccalaureate & $26(66.7)$ & $51(71.8)$ & $53(63.1)$ & $38(82.6)$ & $168(70.0)$ \\
\hline Master's & $4(10.3)$ & $8(11.3)$ & $11(13.1)$ & $2(4.3)$ & $25(10.4)$ \\
\hline Doctoral & $0(0)$ & $0(0)$ & $1(1.2)$ & $0(0)$ & $1(0.4)$ \\
\hline \multicolumn{6}{|c|}{ Years of RN experience } \\
\hline $1-4$ & $7(17.9)$ & $11(15.5)$ & $9(10.7)$ & $10(21.7)$ & $37(15.4)$ \\
\hline $5-9$ & $16(41.0)$ & $30(42.3)$ & $28(33.3)$ & $21(45.7)$ & $95(39.6)$ \\
\hline $10-19$ & 7 (17.9) & $24(33.8)$ & $23(27.4)$ & $6(13.0)$ & $60(25.0)$ \\
\hline$\geq 20$ & $8(20.5)$ & $6(8.5)$ & $23(27.4)$ & $9(19.6)$ & $46(19.2)$ \\
\hline
\end{tabular}

Note. Values are expressed as number (\%) unless otherwise indicated. Percentage may not add up to $100 \%$ because of missing data or rounding. 


\subsection{J ob satisfaction, burnout, compassion satisfaction, \& secondary traumatic stress}

The internal consistency reliabilities, as measured by Cronbach's alpha, were $0.88,0.72,0.88$, and 0.80 for Job Satisfaction, Burnout, Compassion Satisfaction, and Secondary Traumatic Stress subscales, respectively. Mean scores by units are shown in Table 2. The mean job satisfaction and compassion satisfaction scores were lowest for the surgical unit (3.29 and 39.0, respectively) and highest for the hematology/oncology unit (4.26 and 43.0, respectively). The burnout scores showed highest burnout for the surgical unit (24.5) and lowest for the hematology/oncology unit (20.2). The secondary traumatic stress scores were quite similar across the four units, ranging from 21.6 to 22.1 and were not statistically different across the units $\left(F_{3,236}=0.111 ; p=.953\right)$. The mean score differences across the four units were statistically significant for job satisfaction $\left(F_{3,234}=15.561 ; p<.001\right)$, compassion satisfaction $\left(F_{3,236}=5.421 ; p=.001\right)$, and burnout $\left(F_{3,236}=6.361 ; p<.001\right)$.

Table 2. Job satisfaction, burnout, compassion satisfaction, \& secondary traumatic stress scores (mean $\pm \mathrm{SD}$ )

\begin{tabular}{llllll}
\hline & $\begin{array}{l}\text { Surgical unit } \\
(\mathrm{n}=39)\end{array}$ & $\begin{array}{l}\text { Medical unit } \\
(\mathrm{n}=71)\end{array}$ & $\begin{array}{l}\text { Critical care unit } \\
(\mathrm{n}=39)\end{array}$ & $\begin{array}{l}\text { Hematology/oncology unit } \\
(\mathrm{n}=46)\end{array}$ & $\begin{array}{l}\text { Total } \\
(\mathrm{N}=240)\end{array}$ \\
\hline Job satisfaction & $3.29 \pm 0.75$ & $3.87 \pm 0.64$ & $3.59 \pm 0.82$ & $4.26 \pm 0.51$ & $3.75 \pm 0.77$ \\
Compassion satisfaction & $39.0 \pm 5.5$ & $41.7 \pm 4.4$ & $40.8 \pm 4.7$ & $43.0 \pm 4.5$ & $41.2 \pm 4.8$ \\
Burnout & $24.5 \pm 5.1$ & $22.8 \pm 4.7$ & $23.0 \pm 4.7$ & $20.2 \pm 3.9$ & $22.6 \pm 4.8$ \\
Secondary traumatic stress & $21.6(4.5)$ & $22.1(5.2)$ & $22.0(5.9)$ & $21.8(4.9)$ & $22.0(5.3)$ \\
\hline
\end{tabular}

Note. Compassion Satisfaction, Burnout, and Secondary Traumatic Stress subscales: Possible ranges 10-50. Job Satisfaction scale: Possible ranges 1-5.

Figure 1 shows the mean scores for job satisfaction, compassion satisfaction, burnout, and secondary traumatic stress by years of RN experience at each unit. The mean job satisfaction and compassion satisfaction scores in the surgical unit showed the lowest satisfaction for the nurses with 5-9 years of RN experience ( 2.88 and 36.2, respectively) and the highest satisfaction for those with $\geq 20$ years of experience ( 3.81 and 43.4, respectively). The surgical unit's mean burnout and secondary traumatic stress scores were the highest for the nurses with 5-9 years of RN experience (26.6 and 23.2, respectively) and the lowest for those with $\geq 20$ years of experience (20.9 and 18.1, respectively). In contrast, the mean job satisfaction and compassion satisfaction scores for those in hematology/oncology unit were consistently high across the years of $\mathrm{RN}$ experience and the burnout scores were consistently low.

\subsection{Predictors of job satisfaction, burnout and compassion satisfaction}

Bivariate correlations showed that ethnicity, educational level, unit location, and years of RN experience have significant association with job satisfaction scores (see Table 3). For compassion satisfaction and burnout, the unit location had significant correlations. None of the demographic variables had significant correlations with secondary traumatic stress scores. The demographic variables with significant correlations with job satisfaction were entered into simultaneous multiple regression models to identify the predictor variables for job satisfaction, burnout, compassion satisfaction, and secondary traumatic stress. Normality, linearity, and homoscedasticity were met for model assumptions ${ }^{[26]}$.

Table 4 shows that the combination of demographic variables explained $25.1 \%$ of the variance in job satisfaction $\left(R^{2}=\right.$ $0.251)$. The positive predictors of job satisfaction were white ethnicity $(\beta=0.33 ; p=.001)$ and hematology/oncology unit $(\beta=0.16 ; p=0.022)$, whereas negative predictors were surgical unit $(\beta=-0.32 ; p<0.001)$ and critical care unit $(\beta=-0.20$; $p=.005)$. For compassion satisfaction, the combination of demographic variables explained $8.8 \%$ of variance $\left(R^{2}=0.088\right)$ and surgical unit was the only predictor $(\beta=-0.24 ; p=.001)$. For burnout, the combination of demographic variables accounted for $10 \%$ of the variance $\left(R^{2}=0.010\right)$; surgical unit $(\beta=0.15 ; p=.043)$ and hematology/oncology unit $(\beta=-0.22$; $p=.004)$ were significant predictor variables. No statistically significant predictors were identified for secondary traumatic stress. 

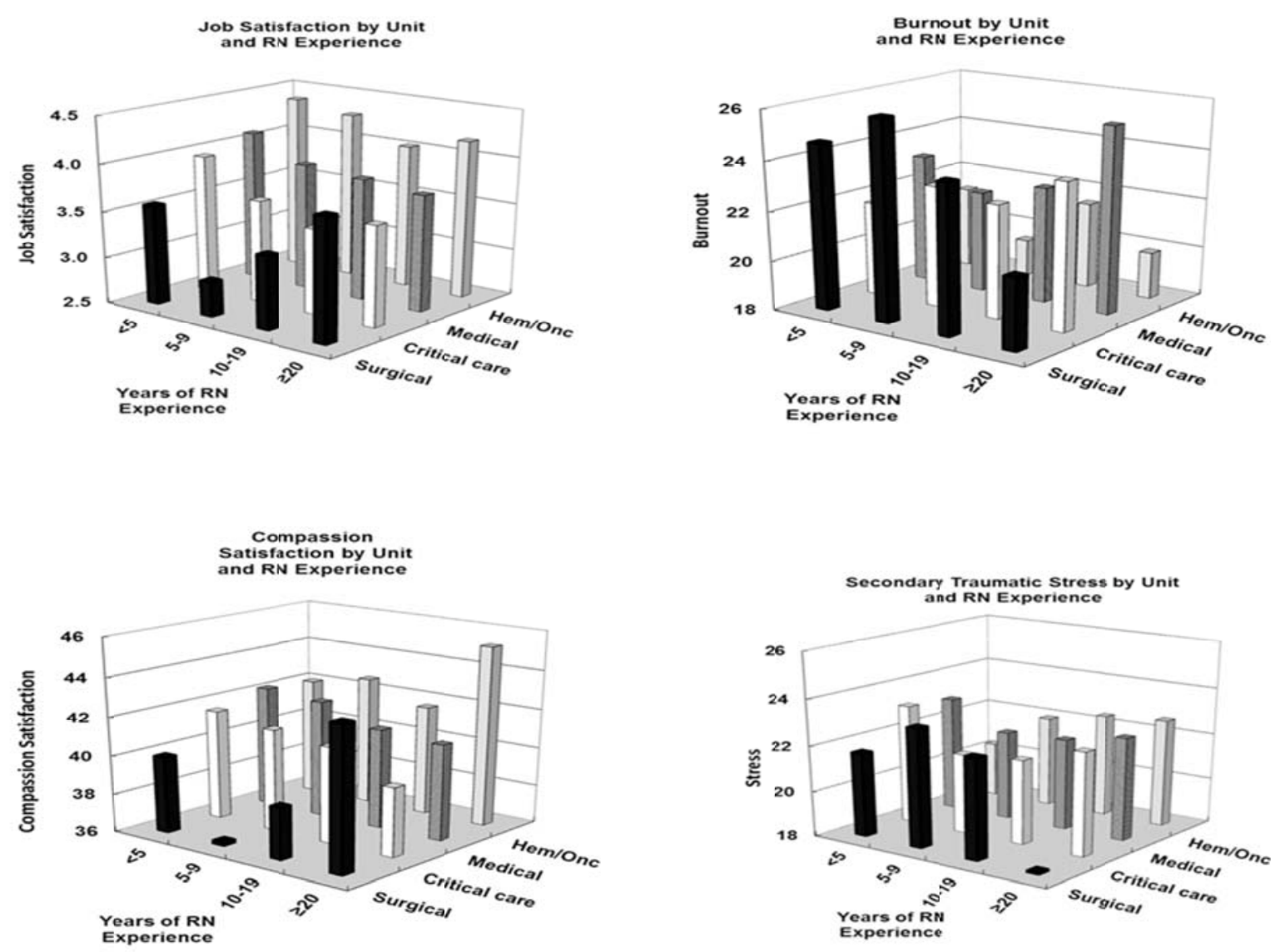

Figure 1. Job satisfaction, burnout, compassion satisfaction, secondary traumatic stress by units and years of RN experience

Table 3. Bivariate correlations $(\mathrm{N}=240)$

\begin{tabular}{|c|c|c|c|c|}
\hline & Job satisfaction $^{\dagger}$ & Compassion satisfaction $^{\dagger, \star}$ & Burnout $^{\dagger, *}$ & Secondary traumatic stress ${ }^{\dagger, \star}$ \\
\hline \multicolumn{5}{|l|}{ Ethnicity } \\
\hline White & $0.153^{*}$ & & & \\
\hline Hispanic & -0.063 & & & \\
\hline Asian/Pacific Islander & -0.005 & & & \\
\hline \multicolumn{5}{|l|}{ Educational level } \\
\hline Diploma/Associate & -0.101 & & & \\
\hline Baccalaureate & $0.138^{*}$ & & & \\
\hline Master's/Doctoral & -0.076 & & & \\
\hline \multicolumn{5}{|l|}{ Unit location } \\
\hline Surgical & $-0.265^{* *}$ & $-0.198 * *$ & $0.169 * *$ & -0.032 \\
\hline Medical & 0.102 & 0.072 & 0.017 & 0.024 \\
\hline Critical care & $-0.159 *$ & -0.062 & 0.056 & 0.011 \\
\hline Hematology/oncology & $0.322 * *$ & $0.178^{* *}$ & $-0.245^{* *}$ & -0.011 \\
\hline \multicolumn{5}{|l|}{ Years of RN experience } \\
\hline $1-4$ & $0.166^{*}$ & & & \\
\hline $5-9$ & -0.044 & & & \\
\hline $10-19$ & -0.094 & & & \\
\hline$\geq 20$ & 0.006 & & & \\
\hline
\end{tabular}

${ }^{\dagger}$ Correlations with gender and age groups were not statistically significant and are not shown. ${ }^{*}$ Correlations with ethnicity, educational level and years of $\mathrm{RN}$ experience were not statistically significant and are not shown. $* p<.05 ; * * p<.01 ; * * * p<.001$ 
Table 4. Simultaneous multiple regression models $(\mathrm{N}=240)$

\begin{tabular}{|c|c|c|c|c|c|c|}
\hline \multirow[t]{2}{*}{ Predictors } & \multicolumn{2}{|c|}{ Job satisfaction } & \multicolumn{2}{|c|}{ Compassion satisfaction } & \multicolumn{2}{|c|}{ Burnout } \\
\hline & B & $\boldsymbol{\beta}$ & B & $\boldsymbol{\beta}$ & B & $\boldsymbol{\beta}$ \\
\hline White ethnicity & 0.16 & $0.33 * *$ & -0.59 & -0.06 & -1.49 & -0.15 \\
\hline Surgical unit & -0.67 & $-0.32 * * *$ & -3.21 & $-0.24 * *$ & 1.93 & $0.15^{*}$ \\
\hline Heme/onc unit & 0.31 & $0.16^{*}$ & 1.02 & 0.08 & -2.60 & $-0.22 * *$ \\
\hline \multirow[t]{3}{*}{ Critical care unit } & -0.32 & $-0.20 * *$ & -1.01 & -0.10 & 0.16 & 0.02 \\
\hline & \multicolumn{2}{|c|}{$R^{2}=0.251$} & \multicolumn{2}{|c|}{$R^{2}=0.088$} & \multicolumn{2}{|c|}{$R^{2}=0.10$} \\
\hline & \multicolumn{2}{|c|}{$F \Delta(11,223)=6.791 * * *$} & \multicolumn{2}{|c|}{$F \Delta(11,225)=1.980^{*}$} & \multicolumn{2}{|c|}{$F \Delta(11,225)=2.264^{*}$} \\
\hline
\end{tabular}

$* p<.05 ; * * p<.01 ; * * * p<.001$ Heme/onc: hematology/oncology

\section{Discussion}

It was an unexpected finding that the nurses in the hematology/oncology unit had the lowest level of burnout and highest levels of compassion satisfaction and job satisfaction among the four units studied. These differences were not only statistically significant, but were also meaningfully different. For example, the burnout scores for hematology/oncology nurses were in the low score category, whereas those for the other units were in moderate score categories. This was confirmed in multivariate analyses that took other demographic variables into account. The hematology/oncology unit was still a positive predictor $(\beta=+0.16)$ of job satisfaction and negative predictor $(\beta=-0.22)$ of burnout. This is in contrast to the previous study results that nurses working in the hematology/oncology units have low job satisfaction, high burnout, and high levels of negative stress related to the intense psychological, emotional, and nursing care required to meet the needs of children with cancer as well as the needs of their families ${ }^{[5,23]}$.

A plausible explanation for this unexpected finding from the current study is that the hematology/oncology unit had previously implemented a unit-based multi-disciplinary patient care program, which embedded palliative and end-of-life care to provide support and comfort measures along with the treatment plans for the children and their families. Since its inception in 2005, the program not only supported children and their families, but also the unit nurses through education and mentoring. This program is led by a Supportive Care Registered Nurse who provides several services and interventional strategies for staff nurses and assists them with specialized education on palliative and end-of-life care. Having a supportive nurse who can serve as an advocate for children and staff nurses may have contributed to low burnout as well as high job satisfaction and compassion satisfaction ${ }^{[28]}$.

On the other hand, the nurses in the surgical unit had the lowest job satisfaction and compassion satisfaction scores as well as the highest burnout scores compared to nurses in other units. One possible explanation is that the surgical unit had undergone significant restructuring over the past few years and had increased patient census and acuities as well as a large number of new staff nurses being hired and trained. Nonetheless, these findings are consistent with a previous study that the pediatric nurses working in the general surgical unit were found to have the highest level of burnout or PTSD symptoms compared to those in medical, oncology, pediatric critical care unit, or emergency room ${ }^{[29]}$.

Although the subgroup sizes by years of RN experience within each unit are relatively small, a closer examination of the data from the surgical unit revealed that those with 5-9 years of RN experience had the lowest job satisfaction and compassion satisfaction with the highest burnout scores, whereas the nurses with greater than 20 years of experience had the highest job satisfaction and lowest burnout scores. In addition, the secondary traumatic stress scores indicate that nurses with 5-9 years of experience in the surgical unit had the highest stress whereas the nurses with greater than 20 years of experience had the lowest stress. It is not clear why the nurses with 5-9 years of experience in the surgical unit have unusually low satisfaction and yet nurses with longest experience have high satisfaction. However, this pattern may be the result of the nurses with high burnout and low job satisfaction leaving the unit selectively, whereas those nurses with low burnout and high job satisfaction are likely to stay in the surgical unit. A similar study finding were reported that the new 
nurses enter the workforce with high satisfaction, which declines over the years, and increase again after 15 years of experience as they become more seasoned and have less job stress ${ }^{[21,30]}$.

Pediatric nursing is a meaningful and rewarding specialty and yet it also offers challenges to nurses with repeated exposure to serious illness, trauma, pain, and suffering of children and their families. Although the unit-based multi-disciplinary patient care program in the hematology/oncology unit appears to have contributed to high job satisfaction and low burnout for the nurses, such a program would not necessarily be useful for nurses in other units since the patient populations served are quite different and the types of stress experienced by nurses are likely to be different as well. Since burnout among nurses is quite prevalent in acute care settings and is negatively associated with quality of nursing care and job satisfaction, it is critical to have strategies for minimizing burnout among nurses at personal, professional, and organizational levels ${ }^{[12,31]}$. On the personal level, nurses need to develop self-care skills in managing family-work balance and coping with stress. At the professional level having mentors as well as supportive and collaborative peers are helpful. The commitment to provide sustainable healthy work environment at each unit, meaningful recognition for staff nurses, open communication between managers and staff, as well as adequate staffing to match patient acuity level are effective strategies at organizational level ${ }^{[32]}$. Considering the need for a variety of strategies at each level, a focused and targeted approach to a specific group of nurses in a unit may be an effective strategy for reducing burnout among pediatric nurses.

\section{Limitations}

There are several limitations to the current study. First, the unit location as a predictor variable for job satisfaction, compassion satisfaction, and burnout should not be taken as cause-and-effect relationships in this cross-sectional study. Second, although the majority of nurses from the units participated in the current study, there was still a significant fraction of nurses who did not participate, which may have introduced sample selection bias. Third, the self-reporting method of the study instruments may have either overestimated or underestimated their responses. Finally, the study findings from a single institution may not be generalizable to other hospital settings.

\section{Conclusions}

Although pediatric nurses in the hematology/oncology unit are thought to have high levels of negative stress from caring for children with cancer, it was surprising that they actually had the lowest level of burnout and highest levels of compassion satisfaction and job satisfaction among the four units studied. In contrast, the nurses in surgical unit had the lowest job satisfaction and compassion satisfaction as well as the highest burnout. A unit-based palliative and end-of-life care program providing support and comfort to the children and family members, as well as education and mentoring for the nursing staff may have contributed to the well-being of the pediatric nurses in hematology/oncology unit. Further studies are needed to confirm the results of the current study and to evaluate the potential effects of interventions to improve professional quality of life and job satisfaction.

\section{Acknowledgement}

Authors wish to express special gratitude to Dottie Crummy, PhD, RN and Chris Sloan, MSN, RN for their helpful suggestions and support.

\section{References}

[1] Neff DF, Cimiotti JP, Heusinger AS, Aiken LH. Nurse reports from the frontlines: analysis of a statewide nurse survey. Nursing Forum. 2011; 46(1): 4-10. PMid:21306390 http://dx.doi.org/10.1111/j.1744-6198.2010.00201.x

[2] Buerhaus PI, DesRoches C, Donelan K, Hess R. Still making progress to improve the hospital workplace environment? Results from the 2008 National Survey of Registered Nurses. Nursing Economics. 2009; 27(5): 289-301. PMid:19927444

[3] International Council of Nurses. The global nursing shortage: priority areas for intervention. Available from: http://www.nurse.or.jp/nursing/international/icn/report/data/2005kangosifusoku.pdf 
[4] Ozden D, Karagozoglu S, Yildirim G. Intensive care nurses' perception of futility: job satisfaction and burnout dimensions. Nursing Ethics. 2013; 20(4): 436-447. PMid:23411368 http://dx.doi.org/10.1177/0969733012466002

[5] Schwerman N, Stellmacher J. A holistic approach to supporting staff in a pediatric hospital setting. Workplace Health \& Safety. 2012; 60(9): 385-390. PMid:22909222 http://dx.doi.org/10.3928/21650799-20120816-51

[6] Toh SG, Ang E, Devi MK. Systematic review on the relationship between the nursing shortage and job satisfaction, stress and burnout levels among nurses in oncology/haematology settings. International Journal of Evidence-based Healthcare. 2012; 10(2): 126-141. PMid:22672602 http://dx.doi.org/10.1111/j.1744-1609.2012.00271.x

[7] Purcell SR, Kutash M, Cobb S. The relationship between nurses' stress and nurse staffing factors in a hospital setting. Journal of Nursing Management. 2011; 19(6): 714-720. PMid:21899624 http://dx.doi.org/10.1111/j.1365-2834.2011.01262.x

[8] Hooper C, Craig J, Janvrin DR, Wetsel MA, Reimels E. Compassion satisfaction, burnout, and compassion fatigue among emergency nurses compared with nurses in other selected inpatient specialties. Journal of Emergency Nursing. 2010; 36(5): 420-427. PMid:20837210 http://dx.doi.org/10.1016/j.jen.2009.11.027

[9] Oyeleye O, Hanson P, O'Connor N, Dunn D. Relationship of workplace incivility, stress, and burnout on nurses' turnover intentions and psychological empowerment. Journal of Nursing Administration. 2013; 43(10): 536-542. PMid:24061587 http://dx.doi.org/10.1097/NNA.0b013e3182a3e8c9

[10] Kearney MK, Weininger RB, Vachon ML, Harrison RL, Mount BM. Self-care of physicians caring for patients at the end of life: "Being connected... a key to my survival". JAMA. 2009; 301(11): 1155-1164. PMid:19293416 http://dx.doi.org/10.1001/jama.2009.352

[11] Stordeur S, D'Hoore W, Group NE-S. Organizational configuration of hospitals succeeding in attracting and retaining nurses. Journal of Advanced Nursing. 2007; 57(1): 45-58. PMid:17184373 http://dx.doi.org/10.1111/j.1365-2648.2006.04095.x

[12] Burtson PL, Stichler JF. Nursing work environment and nurse caring: relationship among motivational factors. Journal of Advanced Nursing. 2010; 66(8): 1819-1831. PMid:20557389 http://dx.doi.org/10.1111/j.1365-2648.2010.05336.x

[13] Hinderer KA, VonRueden KT, Friedmann E, et al. Burnout, compassion fatigue, compassion satisfaction, and secondary traumatic stress in trauma nurses. Journal of Trauma Nursing. 2014; 21(4): 160-169. PMid:25023839 http://dx.doi.org/10.1097/JTN.0000000000000055

[14] Yoder EA. Compassion fatigue in nurses. Applied Nursing Research. 2010; 23(4): 191-197. PMid:21035028 http://dx.doi.org/10.1016/j.apnr.2008.09.003

[15] Robins PM, Meltzer L, Zelikovsky N. The experience of secondary traumatic stress upon care providers working within a children's hospital. Journal of Pediatric Nursing. 2009; 24(4): 270-279. PMid:19632504 http://dx.doi.org/10.1016/j.pedn.2008.03.007

[16] Li A, Early SF, Mahrer NE, Klaristenfeld JL, Gold JI. Group cohesion and organizational commitment: protective factors for nurse residents' job satisfaction, compassion fatigue, compassion satisfaction, and burnout. Journal of Professional Nursing. 2014; 30(1): 89-99. PMid:24503320 http://dx.doi.org/10.1016/j.profnurs.2013.04.004

[17] Davis S, Lind BK, Sorensen C. A comparison of burnout among oncology nurses working in adult and pediatric inpatient and outpatient settings. Oncology Nursing Forum. 2013; 40(4): E303-311. PMid:23803274 http://dx.doi.org/10.1188/13.ONF.E303-E311

[18] Rochefort CM, Clarke SP. Nurses' work environments, care rationing, job outcomes, and quality of care on neonatal units. Journal of Advanced Nursing. 2010; 66(10): 2213-2224. PMid:20626479 http://dx.doi.org/10.1111/j.1365-2648.2010.05376.x

[19] Messmer PR, Bragg J, Williams PD. Support programs for new graduates in pediatric nursing. Journal of Continuing Education in Nursing. 2011; 42(4): 182-192. PMid:21462909 http://dx.doi.org/10.3928/00220124-20110324-05

[20] Todaro-Franceschi V. Critical care nurses' perceptions of preparedness and ability to care for the dying and their professional quality of life. Dimensions of Critical Care Nursing. 2013; 32(4): 184-190. PMid:23759913 http://dx.doi.org/10.1097/DCC.0b013e31829980af

[21] Lacey SR, Teasley SL, Cox KS. Differences between pediatric registered nurses' perception of organizational support, intent to stay, workload, and overall satisfaction, and years employed as a nurse in magnet and non-magnet pediatric hospitals: implications for administrators. Nursing Administration Quarterly. 2009; 33(1): 6-13. PMid:19092517 http://dx.doi.org/10.1097/01.NAQ.0000343342.24925.0c

[22] Edmonds C, Lockwood GM, Bezjak A, Nyhof-Young J. Alleviating emotional exhaustion in oncology nurses: an evaluation of Wellspring's "Care for the Professional Caregiver Program". Journal of Cancer Education. 2012; 27(1): 27-36. PMid:22042712 http://dx.doi.org/10.1007/s13187-011-0278-z

[23] Moody K, Kramer D, Santizo RO, et al. Helping the helpers: mindfulness training for burnout in pediatric oncology--a pilot program. Journal of Pediatric Oncology Nursing. 2013; 30(5): 275-284. PMid:24101747 http://dx.doi.org/10.1177/1043454213504497 
[24] Stamm, BH. The concise ProQOL manual. 2nd Ed. Pocatello, ID: 2010. Available from: http://www.proqol.org/uploads/ProQOL_Concise_2ndEd_12-2010.pdf

[25] Thompson ER, Phua FT. A brief indix of affective job satisfation. Group \& Organization Management. 2012; $37(3): 275-307$. http://dx.doi.org/10.1177/1059601111434201

[26] Tabachnick BG, Fidell LS. Using multivariate statistics. 4th ed. Boston, MA: Allyn and Bacon; 2007.

[27] Cohen MZ, Ferrell BR, Vrabel M, Visovsky C, Schaefer B. What does it mean to be an oncology nurse? Reexamining the life cycle concepts. Oncology Nursing Forum. 2010; 37(5): 561-570. PMid:20797948 http://dx.doi.org/10.1188/10.ONF.561-570

[28] Morgan D. Caring for dying children: assessing the needs of the pediatric palliative care nurse. Pediatric Nursing. 2009; 35(2): 86-90. PMid:19472671

[29] Czaja AS, Moss M, Mealer M. Symptoms of posttraumatic stress disorder among pediatric acute care nurses. Journal of pediatric nursing. Aug 2012; 27(4): 357-365. PMid:22703683 http://dx.doi.org/10.1016/j.pedn.2011.04.024

[30] Ernst ME, Messmer PR, Franco M, Gonzalez JL. Nurses' job satisfaction, stress, and recognition in a pediatric setting setting. Pediatric Nursing. 2004; 30(3): 219-227. PMid:15311648

[31] Rourke MT. Compassion fatigue in pediatric palliative care providers. Pediatric Clinics of North America. 2007; 54(5): 631-644. PMid:17933615 http://dx.doi.org/10.1016/j.pcl.2007.07.004

[32] Longo MA, Roussel L, Pennington SL, Hoying C. The frontline clinical manager identifying direct reports' level of practice. Journal of Pediatric Oncology Nursing. 2013; 30(5): 260-268. PMid:23934257 http://dx.doi.org/10.1177/1043454213493506 